\title{
Changing Funding Arrangements and the Production of Scientific Knowledge: Introduction to the Special
} Issue

\author{
Jochen Gläser ${ }^{1}$ - Kathia Serrano Velarde ${ }^{2}$
}

Published online: 29 January 2018

(C) Springer Science+Business Media B.V., part of Springer Nature 2018

\begin{abstract}
With this special issue, we would like to promote research on changes in the funding of the sciences, social sciences, and humanities. Since funding secures the livelihood of researchers and the means to do research, it is an indispensable condition for almost all research; as funding arrangements are undergoing dramatic changes, we think it timely to renew the science studies community's efforts to understand the funding of research. Changes in the governance of science have garnered considerable attention from science studies and higher education research; however, the impact of these changes on the conduct and content of research has not received sufficient attention, and theoretical insights into the connections between funding practices and research practices are few and far between. The aim of this special issue is to contribute to our theoretical understanding of the changing nature of research funding and its impact on the production of scientific knowledge. More specifically, we are interested in the interplay between funding and research practices: What is the impact of institutionalised funding arrangements on the production of scientific knowledge?
\end{abstract}

Keywords Research funding - Research practices - Governance of science · Performance based funding · Project based funding · Research design · Comparison

Kathia Serrano Velarde

kathia.serrano@soziologie.uni-heidelberg.de

1 Technische Universität Berlin, Berlin, Germany

2 Heidelberg University, Heidelberg, Germany 


\section{Why Funding?}

With this special issue, we would like to promote research on changes in the funding of the sciences, social sciences, and humanities. Since funding secures the livelihood of researchers and the means to do research, it is an indispensable condition for almost all research. The increasing dependency of society on knowledge produced by the sciences, social sciences and humanities makes the capacity to fund research an important power base in society, as is illustrated by studies of 'undone science' (Hess 2007; Frickel et al. 2010). As funding arrangements are undergoing dramatic changes, we think it timely to renew the science studies community's efforts to understand the funding of research. Two major trends in particular have the potential to significantly alter the impact of funding on the production of scientific knowledge. First, we observe that financial support for research work is becoming increasingly scarce in relative terms, and often even in absolute terms. Researchers and research organisations find it increasingly difficult to safeguard the continuation of research and face growing complexity in their funding environments, while funders are confronted with more promising and important research activities than they can sustain. Mobilising and allocating research funding has consequently become a problem for both funders and recipients alike (Guston 2000). A second, related trend is that research funding is increasingly used as a means to exercise authority over the production of scientific knowledge (Whitley et al. 2010). Policymakers and funding agencies attempt to influence the conduct and content of research through the modification of funding arrangements: They try to exercise control over the direction of research by incorporating, for instance, public policy goals in funding programmes (Furman et al. 2012), introducing incentives to collaborate with industry and to commercialise funding (Swan et al. 2010), and creating mission-based research organisations (Cruz-Castro et al. 2012). Meanwhile, the overall quality of research is made to increase through competition and selective funding of the best performers (Hicks and Katz 2011). Of course, this has far-reaching implications for the way we conceive of the governance of science - that is, the authority relationships and the value frameworks enacted through research funding. The trends interact and are overlaid by further changes, such as the increasing importance of charities, supranational funding agencies (Nedeva 2013; Luukkonen 2014), and the emergence of new funding schemes for science (Lepori et al. 2007). The diversification of actors attempting to use funding instruments to achieve their goals and the resulting complexity of funding environments confront science studies scholars with quite the ambivalent picture: While some have argued that "multiple funding sources offer opportunities for buffering the effects of more prescriptive policies and maintaining independence" (Morris and Rip 2006: 259), this is by no means inevitable, as many of these new opportunities come with strings attached. It is equally possible that turbulent funding environments increase the dependence of researchers and research organisations on particular funders, or that the funders' specific expectations concerning content limit the accessibility of funding sources. Thus, the more funding is made conditional on research performance or specific content, the more 
difficult it could become for researchers to maintain their individual research programmes, or even the continuation of research at all.

Changes in the governance of science have garnered considerable attention from science studies and higher education research; however, the impact of these changes on the conduct and content of research has not received sufficient attention and theoretical insights into the connections between funding practices and research practices are few and far between. The aim of this special issue is to contribute to our theoretical understanding of the changing nature of research funding and its impact on the production of scientific knowledge. More specifically, we are interested in the interplay between funding and research practices: What is the impact of institutionalised funding arrangements on the production of scientific knowledge, i.e., on research practices and the knowledge produced by these practices?

\section{Targeting Changes in the Funding of Science}

The contributions to this special issue provide specific perspectives on the state of the art, which is why we will limit our comments to a few developments that justify our enterprise. Indeed, scholarly attention has been quite unevenly distributed across trends in research funding, highlighting the institutional design and embeddedness of funding arrangements, the introduction of performance-based funding systems, or the implications of industry funding for scientific work. Although these research strands have all dealt with the impact of funding on research practices, we argue that this connection merits closer empirical attention and-above all-theorisation.

First of all, research has dealt with the emergence and rising influence of funding agencies from the angle of principal-agency theory (Guston 1996; van der Meulen 1998; Braun and Guston 2003). As “intermediary organizations" (Braun 1993), funding agencies effectively influence and regulate micro behaviour while decoupling the researcher from the state (Musselin 2014). Scholarly interest in funding agencies ceased before interesting variations in their relative autonomy from the state and scientific communities (Braun 1998) or field-specific effects on the behaviour of researchers (Morris 2000) were fully investigated and theorised. Attention shifted to the study of funding programmes (Aguilar et al. 1998; Melin and Danell 2006; Heinze 2008; Edler et al. 2014), and here mostly to selection processes (Bornmann and Daniel 2005; Lamont 2009; Luukkonen 2012). This move has certainly been promoted by the growing interest of funders in the efficacy of their funding schemes and the commissioning of evaluation reports (Hornbostel et al. 2009; Thomas and Nedeva 2012; Möller et al. 2016). Yet studies of funding programmes have produced little in terms of generalisable findings regarding the impact of funding schemes on research practices, not least because they mostly focus on single funding programmes.

A second research perspective targets the implementation and implications of performance-based funding systems for research work (Geuna and Martin 2003; Himanen et al. 2009; Hicks 2012). In combination with research evaluation, performance-based funding made universities recognize the importance of research 
as a source of reputation and, more importantly, income (Whitley and Gläser 2007). As the introduction of new public management structures and practices has strongly increased the authority of management over research funding (Paradeise et al. 2009; Coccia 2009), universities' responses to performance-based funding have the potential to trigger changes in research practices. Some scholars have focused on the role of these meso-level structures in mediating and intervening in the acquisition, organisation, and allocation of external research money (Meier and Schimank 2010; Musselin 2014; Aagaard 2015), but research on performance-based funding has yet to develop an analytical framework that marshals a wide range of variables in order to establish clear causal relationships between funding and the content and conduct of research. This includes the consideration of how research organisations relate to an increasingly diversifying funding landscape for scientific research: How do their attempts to simultaneously increase external funding and control relationships between researchers and funding organisations affect the independence of researchers and thus the production of scientific knowledge?

The third long-standing interest of science studies targets the impact of industry collaborations on academic science. Evidence concerning the influence of university-industry projects on research work is mixed. The content of industryfunded projects is obviously negotiated with funders and aligned with their interests. Thus, there is evidence that the research agenda of researchers funded by industry tends to become more applied (Lam 2010) and prioritise certain types of research output. At the same time, industry funding appears to slow down or delay the diffusion of knowledge by imposing secrecy on the research findings or withholding information on the research process (Campbell et al. 2000; Sismondo 2009). Confronted with these effects, it seems that researchers develop different coping strategies that consist in embracing the collaborative arrangement and its specific incentive structure due to a lack of outside options (Goldfarb 2008); actively counteracting the biasing effects of industrial funding (Murray 2010); or avoiding this type of collaboration altogether (Owen-Smith and Powell 2004). ${ }^{1}$ Existing research thus indicates the complexity of the issue and the elusiveness of the causal links between funding and research content. Indeed, understanding the real-time effects of a complicated and turbulent funding environment on scientific work requires more comparative work that allows for the causal attribution of observed effects (Gläser and Laudel 2016) and more in-depth qualitative work investigating the way organisations and individuals cope with this complexity (Krimsky 2013).

This brief account illustrates two main challenges we face in the pursuit of theory building: First, funding practices can no longer be studied in isolation. With very few exceptions, studies have heretofore focused on one particular type of funding scheme or agency. This strategy can yield only little information about the impact of funding on research practices because research practices are likely to be adapted to funding environments rather than to single sources of funding that are but one element of such an environment. Funding environments are complex systems in

\footnotetext{
1 These responses do not necessarily affect research performance. Researchers who compared industryfunded research to publicly funded research found the former to have no effects on scientists' publication performance (Gulbrandsen and Smeby 2005; Beaudry and Allaoui 2012).
} 
which the accessibility and demands of each source affects the attractiveness of all others, which results in a variety of interacting opportunities and constraints for researchers. Second, studies of funding practices have to take into account the complexity of the multilevel dynamic at play. Studying the impact of changing funding arrangements on research conduct and content requires complex approaches that address increasingly dynamic funding environments, the embeddedness of funding in changing governance structures, and the inclusion of the micro level at which new scientific knowledge is created.

These observations motivated the special issue we present here. We invited contributions that address the link between funding and research practices, and discussed them thoroughly during a paper workshop in Heidelberg in summer 2016. We expressly asked the authors to be explicit about the research practices they were investigating and about how the design of funding arrangements translated into concrete epistemic choices. We further encouraged them to embrace the ambivalence of funding effects by developing thick accounts of the research practice rather than taking it for granted.

\section{Overview of Papers in the Special Issue}

Contractual relationships, which seem characteristic of most contemporary funding schemes for research, influence the way researchers relate to their work. They overlay the funding arrangements researchers have with their organisations as well as other types of research funding. It is the dovetailing of different funding streams and their implications for individuals, communities, and organisations alike that contribute to the increasing complexity of funding environments and require us to develop a comprehensive understanding of the institutional embeddedness of research work. Such a comprehensive understanding cannot be developed with one special issue on the subject. We do believe, however, that the points made by the papers in this special issue contribute important insights into the relationship between funding and research practices.

The contribution by Franssen et al. investigates the institutional affordances of research grants by comparing the research funded by projects and prizes across three scientific fields. Their detailed exploration of research funded by prizes and large research grants demonstrates the institutionalisation of specific project structures in grant funding that create constraints not present in prizes. Furthermore, the authors identify funding requirements for breakthrough research that can neither be met by recurrent organisational funding nor by traditional project grants, as the former has become scarce and the latter can be used only for specified purposes in a specified time frame. Although researchers have some freedom in regard to the use of their funds, this freedom does not extend to improving the grantee's organisational environment. Thus, the investigation into the properties of different kinds of funding not only contributes to our understanding of the link between funding and research practices, but also points out limitations to the current proportions of institutional and project funding. 
Harsh et al. extend this view by examining constraints and affordances of industrial and foreign funding of East African computer science research. In their comparative study of two sites in which computer science has been emerging (Nairobi and Kampala), the authors draw a complex picture of African researchers utilising different sources of foreign funding to build and realise their own research agendas. They systematically compare not only funding structures and the role of university teaching at the two sites but also general political contexts, the culture of innovation, institutional structures, and the role of institutional entrepreneurship. They also identify properties of the field of computer science that facilitated its observed emergence in the two East African cities, including low investment costs, the modularity and scalability of projects, strong student interest, and the generic nature of research activities that can be linked to many other fields.

Torka's analysis of doctoral education programmes funded by project grants demonstrates that the project form may be passed on to individual $\mathrm{PhD}$ projects funded by the programmes. His comparative analysis of interactions between the $\mathrm{PhD}$ project and research practices in the social sciences, physics, and astronomy demonstrates that the $\mathrm{PhD}$ student's research in the social sciences is affected most. In the other fields, the project form is ignored or adapted due to the need to define $\mathrm{PhD}$ projects in the context of long-term collective research processes (experimental physics and astronomy) or individualised research processes that primarily depend on the student's creativity (theoretical physics). Thus, Torka shows that the project form carried by project-based funding continues to spread but remains more or less external to research practices because the requirements of successful research are anchored in the epistemic culture of the scientific community.

Serrano Velarde investigates the relationship between applicants and their funding agencies, and thus by extension their scientific communities, by analysing how the justification rhetoric of grant proposals changes over time in two scientific fields, namely political science and organic chemistry. She argues that the increasing competition for project grants leads to a standardisation and rationalisation of grant proposals, which, however, takes different paths depending on the research practices of the discipline. The value of the proposed contribution and the feasibility of the project take centre stage in proposals but are argued for differently in the two fields. While political scientists portray themselves in a complicated and contradictory research landscape, organic chemists cast themselves and their work as part of highly successive networks of experts.

Whitley et al. use a comparative study of the development of three scientific innovations from the fields of physics, biology, and educational research in four European countries to analyse how the changes in research funding described above have affected scientists' research goals and practices. By comparing the political and funding conditions for the development of innovations with different epistemic properties, the authors find that the increased number of actors exercising authority over research goals does not necessarily translate into a plurality of interests. The diversity of funding practices, which is conducive to developing innovations, is particularly endangered when the ratio of recurrent funding to project funding shifts towards the latter, and when the growing standardisation of project cycle times and 
resource packages across funding agencies makes it more difficult for researchers to pursue projects that deviate from the expectations of their scientific communities.

The contribution by Cruz-Castro and Sanz-Menendez, which will be published in one of the following issues due to space limitations, targets the role of public research institutes in mediating the pressures of the funding environment and translating them into concrete incentives for researchers. The authors develop a typology of research organisations that is based on the autonomy of the organisation itself and on the distribution of authority over funding within the organisation. Further, they develop hypotheses about the impact of changing funding arrangements (block grant funding and project funding) on intra-organisational authority relationships between researchers and management.

The papers highlight three important insights regarding the impact of funding on research practices. First, the properties of research grants matter-especially with regard to the degree of autonomy researchers can exercise over their work. Rigid funding conditions limit the autonomy of researchers in spite of an apparent diversity of funding sources. Second, the less organisational funding is available to provide researchers with additional options and slack, the more effective the contractual relationship over the research work of scientists. Finally, trends in the reconfiguration of funding environments empower research communities and their authority over research work but have ambivalent effects for the individual researcher.

\section{Challenges to the Study of Research Funding}

This special issue's focus on the causal effects of changing funding arrangements on research practices has helped us to identify specific lacunas in the current state of the art. It has also promoted exchanges between the authors featured in this special issue, partly concerning their disciplinary take on the subject. The main conclusion arising from these conversations concerns the importance of widening the focus of investigation. We can learn more about the effects of funding on research by looking beyond funding arrangements. It is important that we turn from the often fruitless search for the causal effects of one particular funding scheme to more complex research designs that (1) integrate different levels of investigation and their insights into the social mechanisms underlying research funding; (2) focus on causal explanations that account for this multilevel nature of research funding and knowledge production; and (3) are comparative and/or longitudinal. Our possibility to generalise research findings and thus theorise the implications of funding on research conduct and content is conditional on our ability to explain variance, i.e., the varying effects of funding changes in different fields and on the researcher.

To substantiate these conclusions we wish to highlight three conditions that are likely to moderate the influence of any funding arrangement on research practice. The first condition relates to developments at the meso level of analysis. It is difficult to imagine a study of funding arrangements that avoids questioning the role of the organisational level in embedding and mediating structural changes in these funding arrangements. Although some scholars have investigated the changing authority relationships within research organisations due to financial cutbacks and 
the introduction of performance-based allocation systems, we still know very little about how research organisations shape the ways in which researchers comprehend and embrace their funding choices outside of the organisation. A second condition occurring at the meso level and remaining largely unexplored is the influence of scientific communities on the allocation of material resources. The more research funding relies on the evaluation of research proposals, individual research performances, and research organisations, the stronger the leverage of scientific communities and their elites on the allocation of funding. The governance of research largely relies on peer review to assess both the quality of research and the directions it ought to take. Thus, we could make the argument that although research organisations and the state gain authority over researchers by means of evaluation, they also lose authority vis-á-vis the scientific community in charge of peer review. The leverage held by scientific communities over the allocation of research funding and its implications for researchers, research organisations, and the state requires systematic analysis. Special interest should be given to the effects produced by the increasing competition for resources within a scientific community on the way the community handles both access to resources and the valuation of funding claims. A third condition comprises the field-specific epistemic practices and epistemic conditions of research shaped by the scientific community's subject matter and knowledge about it. Researchers respond to funding opportunities and governance in the light of their perceived opportunities to produce contributions to their community's knowledge. Thus, practices of knowledge production and their epistemic conditions play a crucial role in moderating the effects of funding on both individuals and organisations.

These conditions are cross-cutting in that they must be addressed in all investigations of research funding that intend to establish causal effects. Understanding how researchers experience and cope with this complexity requires a comprehensive picture of their situation. This again illustrates the main point we wish to make with this special issue: Exploring the effects of changing funding arrangements on research practices requires a leap into the complexity of research designs. We need to embrace this complexity by exploring variation-of funding arrangements, epistemic practices, work conditions, and governance contextsrather than avoiding it through the focus on isolated funding schemes. Only by seizing the messiness of variation can we identify changes in research practices and content as causal effects of funding arrangements, i.e., as effects that occur under specific circumstances and through specific mechanisms.

\section{References}

Aagaard, Kaare. 2015. How Incentives Trickle Down: Local Use of a National Bibliometric Indicator System. Science and Public Policy 42: 725-737.

Aguilar, Alfredo, Torbjörn Ingemansson, Stéphane Hogan, and Etienne Magnien. 1998. Peer Review Evaluation of Proposals in the Biotechnology Programme of the European Union. Research Evaluation 7(3): 141-146.

Beaudry, Catherine, and Sedki Allaoui. 2012. Impact of Public and Private Research Funding on Scientific Production: The Case of Nanotechnology. Research Policy 41(9): 1589-1606. 
Bornmann, Lutz, and Hans-Dieter Daniel. 2005. Selection of Research Fellowship Recipients by Committee Peer Review: Analysis of Reliability, Fairness and Predictive Validity of Board of Trustees' Decisions. Scientometrics 63(2): 297-320.

Braun, Dietmar. 1993. Who Governs Intermediary Agencies? Principal-Agent Relations in Research Policy-Making. Journal of Public Policy 13(2): 135.

Braun, Dietmar. 1998. The Role of Funding Agencies in the Cognitive Development of Science. Research Policy 27(8): 807-821.

Braun, Dietmar, and David H. Guston. 2003. Principal-Agent Theory and Research Policy: An Introduction. Science and Public Policy 30(5): 302-308.

Campbell, Eric G., Joel Weissman, Nancyanne Causino, and David Blumenthal. 2000. Data Withholding in Academic Medicine: Characteristics of Faculty Denied Access to Research Results and Biomaterials. Research Policy 29(2): 303-312.

Coccia, Mario. 2009. Bureaucratization in Public Research Institutions. Minerva 47: 31-50.

Cruz-Castro, Laura, Luis Sanz-Menéndez, and Catalina Martínez. 2012. Research Centers in Transition: Patterns of Convergence and Diversity. Journal of Technology Transfer 37(1): 18-42.

Edler, Jakob, Daniela Frischer, Michaela Glanz, and Michael Stampfer. 2014. Funding IndividualsChanging Organisations: The Impact of the ERC on Universities. In Organizational Transformation and Scientific Change: The Impact of Institutional Restructuring on Universities and Intellectual Innovation, eds. Richard Whitley, and Jochen Gläser, 77-109. Bingley: Emerald Group Publishing Limited.

Frickel, Scott, Sahra Gibbon, Jeff Howard, Joanna Kempner, Gwen Ottinger, and David J. Hess. 2010. Undone Science: Charting Social Movement and Civil Society Challenges to Research Agenda Setting. Science, Technology, and Human Values 35(4): 444-473.

Furman, Jeffrey L., Fiona Murray, and Scott Stern. 2012. Growing Stem Cells: The Impact of Federal Funding Policy on the U.S. Scientific Frontier. Journal of Policy Analysis and Management 31(3): 661-705.

Geuna, Aldo, and Ben R. Martin. 2003. University Research Evaluation and Funding: An International Comparison. Minerva 41: 277-304.

Gläser, Jochen, and Grit Laudel. 2016. Governing Science: How Science Policy Shapes Research Content. European Journal of Sociology 57(1): 117-168.

Goldfarb, Brent. 2008. The Effect of Government Contracting on Academic Research: Does the Source of Funding Affect Scientific Output? Research Policy 37(1): 41-58.

Gulbrandsen, Magnus, and Jens-Christian Smeby. 2005. Industry Funding and University Professors' Research Performance. Research Policy 34(6): 932-950.

Guston, David. 1996. Principal-Agent Theory and the Structure of Science Policy. Science and Public Policy 23(4): 229-240.

Guston, David. 2000. Between Politics and Science: Assuring the Integrity and Productivity of Research. Cambridge: Cambridge University Press.

Heinze, Thomas. 2008. How to Sponsor Ground-Breaking Research: A Comparison of Funding Schemes. Science and Public Policy 35(5): 302-318.

Hess, David. 2007. Alternative Pathways in Science and Industry: Activism, Innovation, and the Environment in an Era of Globalization. Cambridge: MIT Press.

Hicks, Diana. 2012. Performance-Based University Research Funding System. Research Policy 41(2): 251-261.

Hicks, Diana, and J. Sylvan Katz. 2011. Equity and Excellence in Research Funding. Minerva 49(2): 137-151.

Himanen, Laura, Otto Auranen, Hanna-Maria Puuska, and Mika Nieminen. 2009. Influence of Research Funding and Science Policy on University Research Performance: A Comparison of Five Countries. Science and Public Policy 36(6): 419-430.

Hornbostel, Stefan, Susan Böhmer, Bernd Klingsporn, Jörg Neufeld, and Markus von Ins. 2009. Funding of Young Scientist and Scientific Excellence. Scientometrics 79: 171-190.

Krimsky, Sheldon. 2013. Do Financial Conflicts of Interest Bias Research? An Inquiry into the 'Funding Effect' Hypothesis. Science, Technology, and Human Values 38(4): 566-587.

Lam, Alice. 2010. From 'Ivory Tower Traditionalists' to 'Entrepreneurial Scientists'? Social Studies of Science 40(2): 307-340.

Lamont, Michèle. 2009. How Professors Think: Inside the Curious World of Academic Judgment. Cambridge, Mass.: Harvard University Press. 
Lepori, Benedetto, Peter van den Besselaar, Michael Dinges, Bianca Potì, Emanuela Reale, Stig Slipersæter, et al. 2007. Comparing the Evolution of National Research Policies: What Patterns of Change? Science and Public Policy 34(6): 372-388.

Luukkonen, Terttu. 2012. Conservatism and Risk-Taking in Peer Review: Emerging ERC Practices. Research Evaluation 21(1): 48-60.

Luukkonen, Terttu. 2014. The European Research Council and the European Research Funding Landscape. Science and Public Policy 41(1): 29-43.

Meier, Frank, and Uwe Schimank. 2010. Mission Now Possible: Profile Building and Leadership in German Universities. In Reconfiguring Knowledge Production: Changing Authority Relationships in the Sciences and their Consequences for Intellectual Innovation, eds. Richard Whitley, Jochen Gläser, and Lars Engwall, 211-236. Oxford: Oxford University Press.

Melin, Göran, and Rickard Danell. 2006. The Top Eight Percent: Development of Approved and Rejected Applicants for a Prestigious Grant in Sweden. Science and Public Policy 33(10): 702-712.

Morris, Norma. 2000. Science Policy in Action: Policy and the Researcher. Minerva 38(4): 425-451.

Morris, Norma, and Arie Rip. 2006. Scientists' Coping Strategies in an Evolving Research System: The Case of Life Scientists in the UK. Science and Public Policy 33(4): 253-263.

Möller, Torger, Marion Schmidt, and Stefan Hornbostel. 2016. Assessing the Effects of the German Excellence Initiative with Bibliometric Methods. Scientometrics 109(3): 2217-2239.

Musselin, Christine. 2014. Empowerment of French Universities by Funding and Evaluation Agencies. In Organizational Transformation and Scientific Change: The Impact of Institutional Restructuring on Universities and Intellectual Innovation, eds. Richard Whitley, and Jochen Gläser, 51-76. Bingley: Emerald Group Publishing Limited.

Murray, Fiona. 2010. The Oncomouse That Roared: Hybrid Exchange Strategies as a Source of Distinction at the Boundary of Overlapping Institutions. American Journal of Sociology 116(2): 341-388.

Nedeva, Maria. 2013. Between the Global and the National: Organising European Science. Research Policy 42(1): 220-230.

Owen-Smith, Jason, and Walter W. Powell. 2004. Carrières et contradictions en sciences de la vie. Réponses du corps académique aux transformations de la connaissance et de ses utilisations. Sociologie du Travail 46(3): 347-377.

Paradeise, Catherine, Emanuela Reale, Ivar Bleiklie, and Ewan Ferlie (eds.). 2009. University Governance-Western European Comparative Perspectives. Dordrecht: Springer Science and Business Media.

Sismondo, Sergio. 2009. Ghosts in the Machine: Publication Planning in the Medical Sciences. Social Studies of Science 39(2): 171-198.

Swan, Jacky, Mike Bresnen, Maxine Robertson, Sue Newell, and Sue Dopson. 2010. When Policy Meets Practice: Colliding Logics and the Challenges of 'Mode 2' Initiatives in the Translation of Academic Knowledge. Organization Studies 31(9-10): 1311-1340.

Thomas, Duncan, and Maria Nedeva. 2012. Characterizing Researchers to Study Research Funding Agency Impacts: The Case of the European Research Council's Starting Grants. Research Evaluation 21(4): 257-269.

van der Meulen, Barend. 1998. Science Policies as Principal-Agent Games: Institutionalization and Path Dependency in the Relation between Government and Science. Research Policy 27(4): 397-414.

Whitley, Richard, Jochen Gläser, and Lars Engwall (eds.). 2010. Reconfiguring Knowledge Production: Changing Authority Relationships in the Sciences and their Consequences for Intellectual Innovation. Oxford: Oxford University Press.

Whitley, Richard, and Jochen Gläser (eds.). 2007. The Changing Governance of the Sciences: The Advent of Research Evaluation Systems. Dordrecht: Springer. 